\title{
DETERMINATION OF THE BENZENE AND THE NORMAL HEXANE CONTENT IN A MID-CONTINENT PETRO- LEUM $^{1}$
}

\author{
By Johannes H. Bruun ${ }^{2}$ and Mildred M. Hicks-Bruun
}

\begin{abstract}
The benzene content of fractions of a mid-continent petroleum has been determined by converting the benzene to $m$-dinitrobenzene. All of the benzene was found as a constant boiling mixture with the hexanes in the fractions boiling below the boiling point of pure benzene. The large fraction boiling between $69^{\circ}$ and $70^{\circ} \mathrm{C}$. contained the greatest amount of benzene. The greatest concentration (6.5 per cent of benzene) was found in the $68^{\circ}$ to $69^{\circ}$ fraction. Based upon the crude petroleum the benzene content was found to be 0.08 per cent. A sample of pure benzene was isolated from its constant boiling mixture by extracting with aniline and successive equilibrium melting.

The $n$-hexane content of the crude petroleum has been estimated to be about one-third per cent. This is more than the combined amounts of the other isomers of hexane. A sample of pure $n$-hexane has been isolated by treatment with chlorosulphonic acid.

Time-temperature cooling curves, as well as the following physical constants, have been determined for the isolated hydrocarbons: Freezing point, boiling point, density, and refractive index. All of these constants agree well with those of the synthetic hydrocarbons.

The benzene-hexane ratio of a petroleum oil is the determining factor with respect to the temperature at which the benzene distills.

The boiling ranges have been accurately determined by means of a continuous boiling-point apparatus which has been placed in the distillation system between the top of the column and the condenser. The advantages of this method are discussed.
\end{abstract}

\section{CONTENTS}

I. Introduction

II. Experimental procedure

1. Distillation

2. Nitration of benzene

3. Extraction of benzene....

4. Isolation of $n$-hexane.

III. Discussion of the results

1. Benzene

2. $n$-Hexane $\ldots \ldots \ldots$

IV. Acknowledgment.

1 This paper described some of the results obtained in an investigation on the separation, identification, and determination of the chemical constituents of commercial petroleum fractions listed as project No. 6 of the American Petroleum Institute Research. Financial assistance in this work has been recelved from a research fund of the American Petroleum Institute donated by John D. Rockefeller. This fund is being administered by the institute with the cooperation of the central petroleum committee of the nationsl research council.

2 American Petroleum Institute research associate. 


\section{INTRODUCTION}

The presence of benzene in American petroleum was established as early as 1863 by Schorlemmer ${ }^{3}$, who found that some nitrobenzene was formed, when a fraction from Pennsylvania petroleum was boiled with nitric acid. Mabery, ${ }^{4}$ in his pioneer work on American petroleum, found that, in the distillation of an Ohio crude oil, benzene concentrated in the fractions boiling between $75^{\circ}$ and $86^{\circ} \mathrm{C}$. The greatest concentration of benzene ( 15 per cent) was found in the fraction boiling between $79^{\circ}$ and $81^{\circ} \mathrm{C}$., or, in other words, around the boiling point of pure benzene $\left(80.2^{\circ} \mathrm{C}\right.$. $)$. Based upon the crude oil, Mabery estimated that the Ohio petroleum contained 0.017 per cent of benzene. Mabery's method consisted of nitrating the benzene to mononitrobenzene and weighing it as such. Mabery and Hudson ${ }^{5}$ found that the bulk of the benzene from a California petroleum also collected in the fractions distilling between $79^{\circ}$ and $81^{\circ} \mathrm{C}$.

On the other hand, Young, ${ }^{6}$ in his work on Pennsylvania petroleum, found that all of the benzene distilled over far below its normal boiling point and that it concentrated largely in the fractions boiling at about $65^{\circ}$ to $66^{\circ} \mathrm{C}$. The reason for this is that constant-boiling mixtures (with minimum boiling point) are formed between benzene and the hexanes. Young determined the benzene by nitrating it to its dinitro derivative.

The isolation of the isomers of hexane has been discussed in a previous paper. ${ }^{7}$ In the present investigation some additional information has been obtained concerning the approximate amounts in which these isomers of hexane are present in the petroleum.

\section{EXPERIMENTAL PROCEDURE}

\section{DISTILLATION 8}

The material for this investigation was obtained from an Oklahoma oil ficld. 600 gallons of crude oil from a single well ${ }^{9}$ was subjected to a preliminary distillation in an oil refinery. The fractions thus obtained were first redistilled twice in a rectifying still ${ }^{10}(20-$ liter capacity) with 20 bubbling-cap plates of steel. ${ }^{11}$ The lower boiling fractions from these distillations were then subjected to a final distillation through a 30-plate rectifying column ${ }^{11}$ of Pyrex laboratory glass. This distillation was carried out at a rate of about 2 $\mathrm{ml}$ per minute with a reflux ratio of about $10: 1$. The final distribution of the fractions with respect to their boiling range is shown by Graph I, in Figure 2.

Instead of the usual method of reading the condensation temperature at the top of the column the following method has been dereloped, in accordance with a suggestion by $\mathrm{E}$. W. Washburn. The

\footnotetext{
${ }^{8}$ C. Schorlommer, Ann., 127, p. 311; 1863

C. F. Mabery, Proc. Am. Ac., 31, p. 34; 1894

C. F. Mahery and E. J. Hudson, Proc. Am. Ac., 36, p. 259; 1901.

6 . Young, J. Chom. Soc., 73, p. 914; 1898.

7 J. H. Iruun and M. M. Hicks-Bruun, B. S. Jour Research, 5 . $033-42,1030$

7. The final distillation fractionation was carried out by S. T. Schicktanz and a staff of still operators.

Bruuell No. 6 of the South Ponca Field, Kay County, Okla. For properties, see E. W. Washburn, J. H.

Bruun, and M. M. Hicks, B. S. Jour. Research, 2, p. 469, Table 1; 1929.

10 E. W. Washburn, J. H. Bruun, M. M. Hicks, B. S. Jour. Research, 2, pp. 470-3; 1929.

u J. H. Bruun, Ind. Eng. Chem., Anal. ed., 1, p. 212; 1929.
} 
distillate, after leaving the top of the column, is allowed to pass down into a Cottrell ${ }^{12}$ boiler as shown in Figure 1. The hot liquid from the top of the retifying column enters the boiler at $A$, and by means of an electric heating coil, $H$, in the bell, $B$, is kept boiling continuously. A mixture of vapor and boiling liquid ascends from the

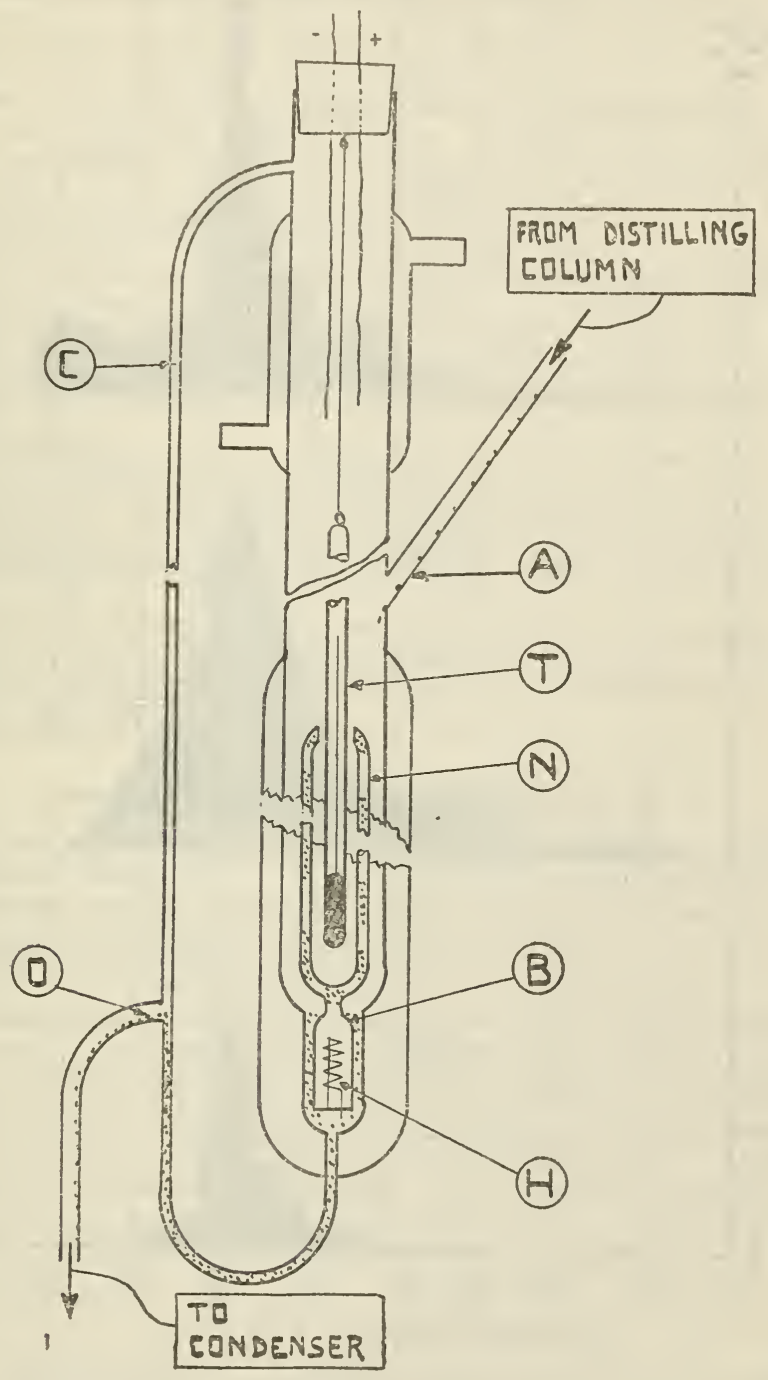

Figure 1.-A continuous boiling point apparatus

The lower part of the apparatus in Figure 1 is insulated by a vacuum jacket, as shown.

bell, $B$, through the narrow tubes, $N$, and is discharged against the thermometer, $T$. The liquid overflows continuously through $O$ into the condenser and receiver unit of the still. The main advantages of this method of reading the distillation temperatures are: (1) The method gives the true boiling point rather than the "condensa- 
tion" point, which is the usual one obtained at the top of a rectifying" column; and (2) greater precision as well as convenience in reading the thermometer, because the Cottrell boiler may be placed at any convenient level in the laboratory:

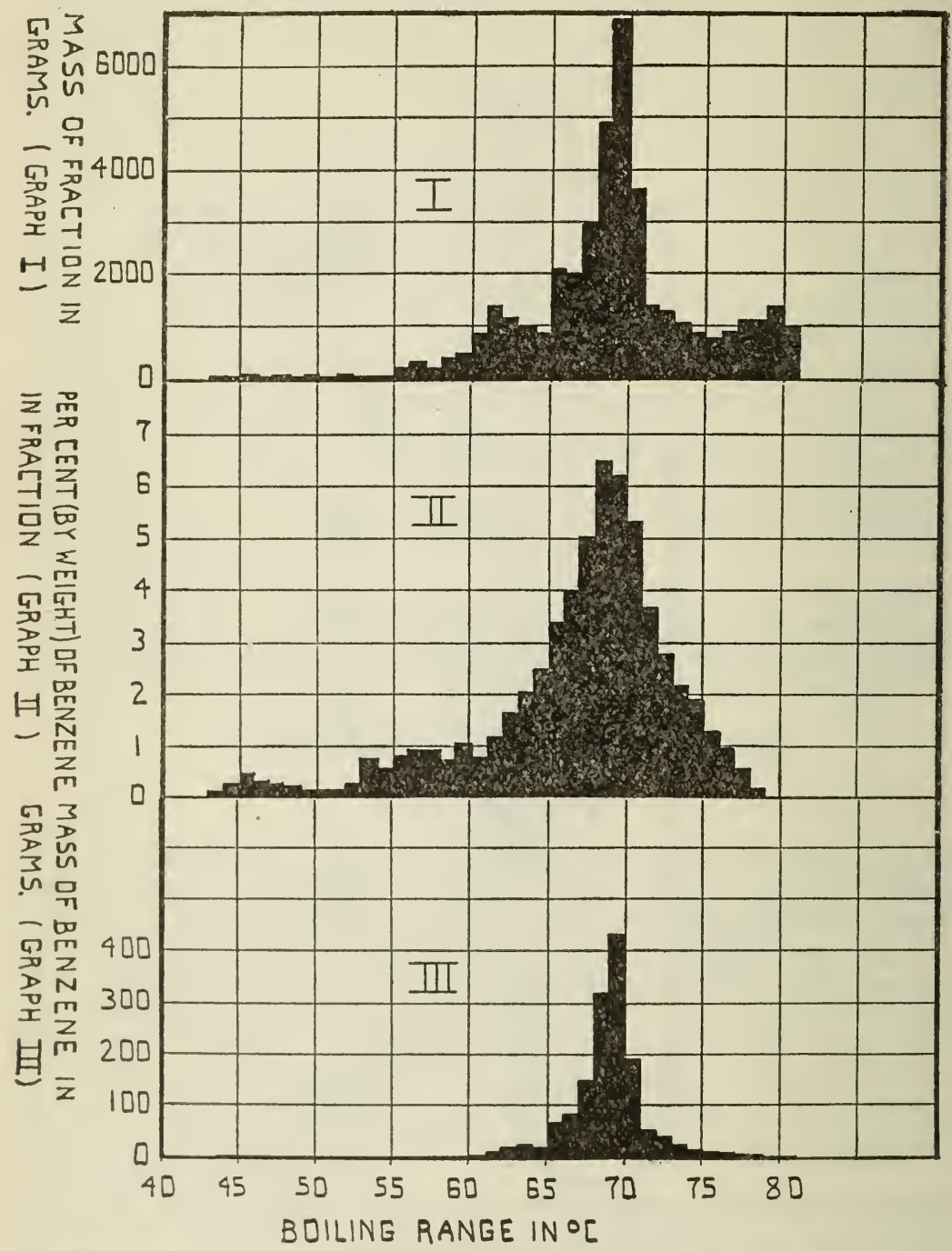

PIgURE 2.-Mass data plotted against boiling range of fraction

\section{NITRATION OF BENZENE}

As a result of the distillation, 37 one-degree cuts were obtained between $44^{\circ}$ and $81^{\circ} \mathrm{C}$, as shown in Graph I, Figure 2. The benzene in each of these cuts was then converted into $m$-dinitrobenzene by a nitrating method similar to that previously used ${ }^{13}$ for the determin-

13 J. H. Bruun, R. T. Leslie, S. T. Schicktanz, B. S. Jour. Research, 0, pp. 363-367; 1931. 
ation of toluene. However, as it is well known that the reactivity of benzene toward nitric acid is less than that of its homologues, it was necessary to use a large excess of nitrating acid and very vigorous agitation for a long time in order to obtain quantitative conversion. During the nitration the temperature was kept below $10^{\circ} \mathrm{C}$. by means of a continuous stream of tap water through the cooling bath.

Before nitration, the absence of olefine hydrocarbons was proved by testing with bromine. A check run on an unnitrated benzenefree fraction indicated that the nitrating treatment did not remove or attack the aliphatic hydrocarbons. A nitration was also carried out on a synthetic mixture of olefin and aromatic-free petroleum ether to which known amounts of benzene were added. A quantitative yield of dinitrobenzene was obtained.

Because small amounts of dinitrobenzene remain in solution in the petroleum fraction after nitration, a corresponding correction was made in calculating the benzene content. The correction was found by determining the solubility of $m$-dinitrobenzene in the fraction. This was in every case less than $0.2 \mathrm{~g}$ dinitrobenzene per 100 $\mathrm{g}$ of hydrocarbons.

After each nitration the melting point of the dried nitro product was determined. All of the melting points were close to that of $m$-dinitrobenzene and by recrystallization of the material they could easily be raised to the accepted melting point of this compound $\left(89.7^{\circ}\right.$ C.).

From the weight of the nitro products the amount of benzene in each fraction was calculated. The results of the nitration are shown in Figure 2, Graphs II and III.

\section{EXTRACTION OF BENZENE}

From some of the fractions benzene was removed by extraction with aniline at about $0^{\circ} \mathrm{C}$. This was done as illustrated in Figure $3 . .^{14}$ The apparatus consists of a narrow brass box, $A$, $(80 \mathrm{~cm}$ long $8 \mathrm{~cm}$ high and $4 \mathrm{~cm}$ wide) divided into 20 sections by means of 19 brass plates, $B$. A shaft, $C$, with 17 propeliers, $D$, passes through the entire length of the apparatus. The shaft is rotated by means of a motor, $M$. The plates are provided with narrow vertical slits (not shown in the figure) to allow liquid to pass from one section into another.

The apparatus is operated on the counter-current principle, aniline entering at $F$ and leaving at $G$. The hydrocarbon to be extracted enters at $H$ and overflows through $I$. The two liquid layers are thoroughly mixed by the propellers (about 300 r. p. m.) so that equilibrium is established between the phases. The apparatus is covered with a glass plate, $J$, and is placed in a cooling bath as shown. A sight glass in each end of the apparatus (not shown in the figure) indicates the height of the interface between the two layers. The right-hand side of the apparatus may be lowered or raised by means of the leveling screw, $K$. This permits regulation of the overflow ratio of the two liquids. As indicated by the broken line, the hydrocarbon phase may be recirculated for futher extraction. This can be done either continuously by means of a circulation pump or intermittently by pouring.

14 Acknowledgment is made to F. W. Pose, jr., for the drawing of Fig. 3. 


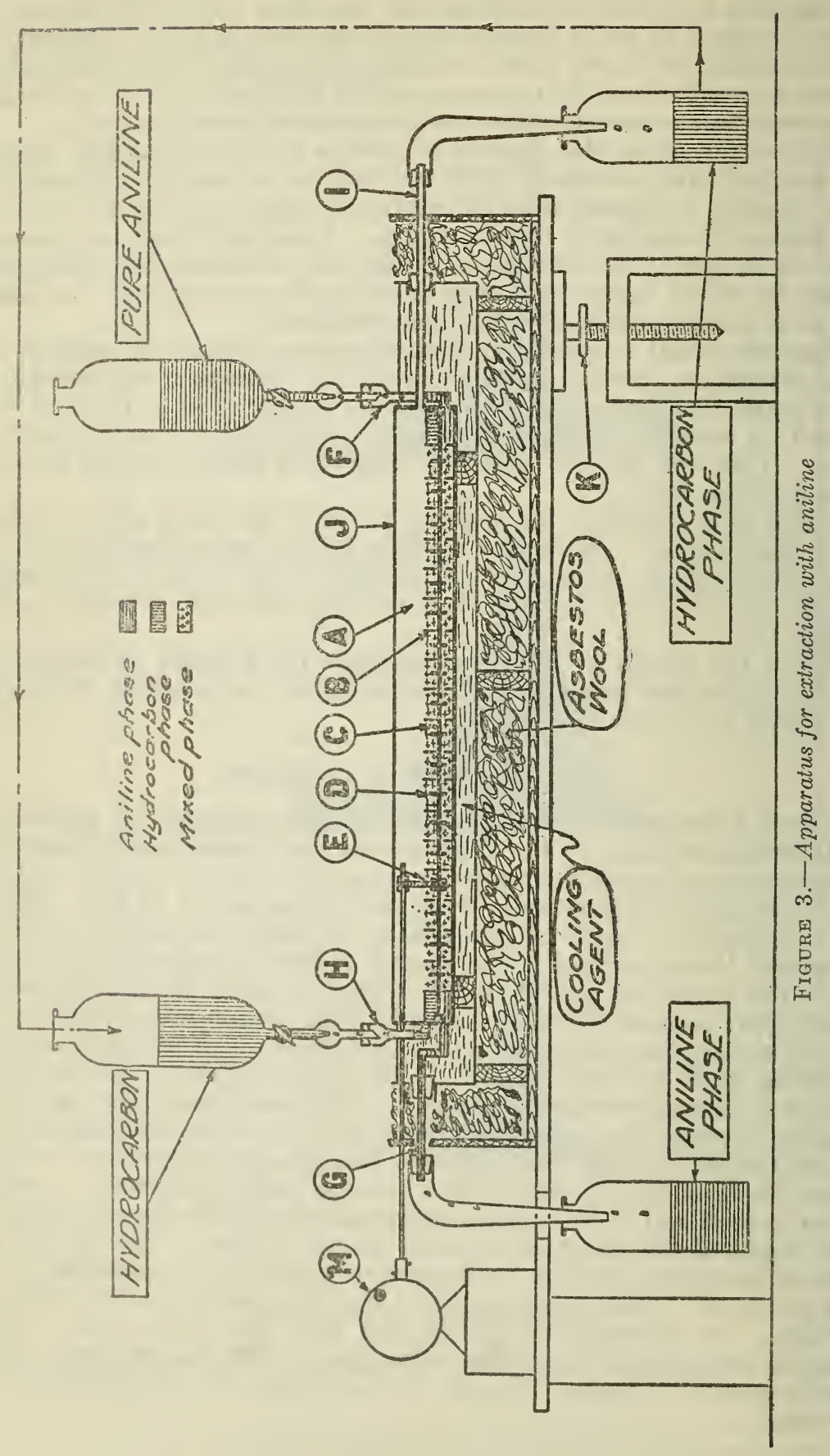


After extraction the hydrocarbon phase is washed with hydrochloric acid and with water until it is free from aniline. 'The aniline phase is distilled and the first distillates, containing the extracted hydrocarbons, are freed from remaining aniline in the same way.

The extraction method was applied to the constant boiling mixture of benzene and $n$-hexane. In this experiment $1,600 \mathrm{ml}$ of the $68^{\circ}$ to $69^{\circ}$ C. cut $\left(n_{\mathbf{D}}^{20}=1.395\right)$ was extracted once as described. As a result 2 fractions were obtained, 1 of $200 \mathrm{ml}$ with $n_{\mathrm{D}}^{20}=1.419$ and 1 about $1,300 \mathrm{ml}$ of material with a refractive index $n_{\mathrm{I}}^{20}=1.391$.

By subjecting the $200 \mathrm{ml}$ fraction to equilibrium melting ${ }^{15}$ a small purified sample of benzene $\left(n_{\mathrm{D}}^{20}=1.501\right)$ was obtained (See p. 877.)

Removal of the benzene by extraction with liquid $\mathrm{SO}_{2}$ was also tried. The apparatus and technic developed by R.T.Leslie, of this bureau were used. A $500 \mathrm{ml}$ portion of the $68^{\circ}$ to $69^{\circ}\left(n_{\mathrm{D}}^{20}=1.395\right)$ cut was split up as follows: $7 \mathrm{ml}$ with $n_{\mathrm{D}}^{20}=1.492,20 \mathrm{ml}$ with $n_{\mathrm{D}}^{20}=$ 1.427 , and $425 \mathrm{ml}$ with $n_{\mathrm{D}}^{20}=1.392$.

\section{ISOLATION OF N-HEXANE}

In order to isolate the $n$-hexane, the fraction boiling at about $69^{\circ}$ C. was treated with chlorosulphonic acid. ${ }^{16}{ }^{17}$ This acid reacts comparatively slowly with the normal hydrocarbons, while the isomers and cyclic compounds are attacked vigorously and destroyed. A $1,000 \mathrm{ml}$ sample of the $69^{\circ}$ to $70^{\circ} \mathrm{C}$. cut was agitated with an equal volume of chlorosulphonic acid (technical) at $40^{\circ}$ to $60^{\circ} \mathrm{C}$. for about 12 hours. The acid sludge was then replaced with fresh acid and the agitation continued for another 12 hours at about $60^{\circ} \mathrm{C}$. After separation from the heavier acid sludge, the hydrocarbon layer was washed in a separatory funnel with 5 per cent $\mathrm{NaOH}$ solution and with water finally dried over $\mathrm{CaCl}_{2}$. After this treatment the material consisted of almost pure hexane which was distilled over sodium in a 10-plate column. ${ }^{18}$ The result of this distillation is shown in Table 1.

TABLE 1.-Distillation of $n$-hexane

\begin{tabular}{|c|c|c|c|}
\hline Fraction No. & $\begin{array}{l}\text { Volume of } \\
\text { fraction }\end{array}$ & $\begin{array}{l}\text { Boiling } \\
\text { point } \\
\text { corrected }\end{array}$ & $\begin{array}{l}\text { Refractive } \\
\text { index } n_{D}^{\circ}\end{array}$ \\
\hline & $\begin{array}{c}m l \\
3 \\
60 \\
60 \\
60 \\
60\end{array}$ & $\begin{array}{l}{ }^{\circ} \mathrm{C} . \\
68.6 \\
68.7 \\
68.7 \\
68.7 \\
68.7\end{array}$ & $\begin{array}{l}1.3799 \\
1.3751 \\
1.3750 \\
1.3750\end{array}$ \\
\hline Pesidue & $\begin{array}{l}60 \\
60 \\
70 \\
90\end{array}$ & $\begin{array}{l}68.7 \\
68.7 \\
68.7\end{array}$ & $\begin{array}{l}\text { 1. } 3751 \\
1.3752 \\
1.3759\end{array}$ \\
\hline
\end{tabular}

Fractions Nos. 4 and 5 were mixed, after which the freezing behavior and the physical constants of the sample were determined. As shown later, these constants agree well with those of the best samples of synthetic $n$-hexane prepared by other investigators.

15 M. M. Hicks, B. S. Jour. Research 2, p. 481; 1929

16 O. Aschan, Ber., 31, p. 1801; 1898.

17 A. F. Shepherd and E. L. Henne, Ind. Eng. Chem., 22, p. 356; 1930.

18 See footnote 11, p. 870 .

$$
49527^{\circ}-31-8
$$




\section{DISCUSSION OF THE RESULTS}

\section{BENZENE}

Graph II in Figure 2 represents the concentration of benzene (in per cent) in the different cuts. The fraction boiling between $68^{\circ}$ and $69^{\circ} \mathrm{C}$. has the highest concentration of benzene, 6.5 per cent.

Graph III in Figure 2, representing the distribution of the benzene in the different fractions, shows that the greatest amount of benzene $(433 \mathrm{~g})$ is present in the large fraction boiling between $69^{\circ}$ and $70^{\circ} \mathrm{C}$. Practically all of the benzene of this petroleum is found in the fractions boiling between $65^{\circ}$ and $75^{\circ} \mathrm{C}$.

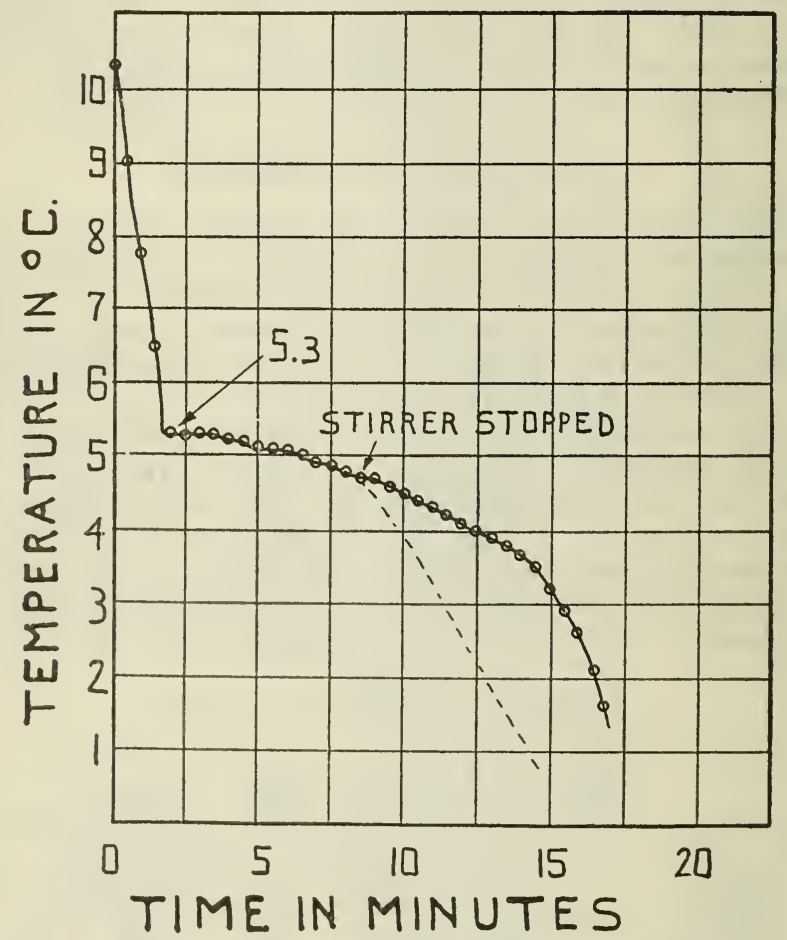

FIGURE 4.-Freezing curve for benzene

It is interesting to note that while the peak for Graph III (mass of benzene in fraction) is exhibited by the fraction boiling between $69^{\circ}$ and $70^{\circ}$ C., Graph II (concentration of benzene in the fraction) reaches its maximum for the fraction distilling between $68^{\circ}$ and $69^{\circ} \mathrm{C}$. This is to be expected in view of the fact that the fraction $69^{\circ}$ to $70^{\circ}$ consists mainly of $n$-hexane and the fact that the constant-boiling mixture of $n$-hexane and benzene has a minimum boiling point. Had this been a maximum boiling point, the peak of Graph II would have fallen to the right of the peak for Graph III.

Another interesting feature of Graph II is the fact that while the right branch rapidly falls toward the abscissa, the left branch falls off at first rapidly and then exhibits a rather irregular behavior. For 
concentrations of benzene below 1 per cent the slope of this left side is nonuniform and only slowly approaches the abscissa. The explanation of this may be found in the fact that the isomers of $n$-hexane ${ }^{19}$ also form constant-boiling mixtures with benzene.

A total yield of $1,530 \mathrm{~g}$ of benzene was obtained. Based upon the original material, 600 gallons of crude oil (specific gravity 0.9 ), it can be concluded that the crude oil contains not less than 0.08 per cent of benzene.

TABLE 2.-Physical constants of benzene

\begin{tabular}{|c|c|c|c|c|}
\hline Benzene & $\begin{array}{l}\text { Normal } \\
\text { boiling } \\
\text { point }\end{array}$ & $\begin{array}{c}\text { Freezing } \\
\text { point } \\
\text { (in air) }\end{array}$ & $\begin{array}{c}\text { Refractive } \\
\text { index } \\
20 \\
n \mathrm{D}\end{array}$ & $\begin{array}{c}\text { Density } \\
20 \\
d 4\end{array}$ \\
\hline 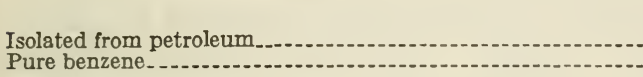 & $\begin{array}{l}{ }^{\circ} \mathrm{C} . \\
80.1 \\
180.2\end{array}$ & $\begin{array}{r}{ }^{\circ} C_{\dot{5}} \\
5.3 \\
15.5\end{array}$ & $\begin{array}{r}1.501 \\
21.5014\end{array}$ & $\begin{array}{l}0.878 \\
2.878\end{array}$ \\
\hline
\end{tabular}

1 J. Timmermans and F. Martin, J. chim. phys., 23, p. 751; 1926.

2 Int. Crit. Tables, 1, p. 198.

The physical constants of the purified sample of this benzene are compared with those of pure benzene in Table 2 . The time-temperature freezing curve of the sample of benzene isolated is shown in Figure 4. As indicated by an arrow, the benzene froze solid after eight minutes, at which time the stirrer had to be stopped. The benzene near the thermometer bulb then cooled more slowly than that near the walls of the tube, and this caused the curve to fall gradually at first, then to drop suddenly. The dotted curve indicates the approximate slope, which would have been expected, if the stirrer could have been kept in operation. The initial freezing point of $5.3^{\circ}$ corresponds to an estimated purity of 99.8 mole per cent.

\section{2. n-HEXANE}

The physical constants of the $n$-hexane isolated from petroleum are shown below.

TABLE 3.-Physical constants of $n$-hexane

\begin{tabular}{|c|c|c|c|c|c|}
\hline$n$-Нехапе & $\begin{array}{c}\text { Boiling } \\
\text { point } \\
760 \mathrm{~mm}\end{array}$ & $\begin{array}{c}\text { Freezing } \\
\text { point } \\
\text { (in air) }\end{array}$ & $\begin{array}{c}\text { Refractive } \\
\text { index } \\
n_{\mathrm{D}}^{20}\end{array}$ & $\begin{array}{c}\text { Density } \\
d_{4}^{20}\end{array}$ & $\begin{array}{l}\text { Aniline } \\
\text { point }\end{array}$ \\
\hline rane isolated from petroleum & ${ }^{\circ} \mathrm{Cl} .7$ & $\begin{array}{l}{ }^{\circ} \mathrm{C} . \\
-95.67\end{array}$ & 1.3750 & 0.6599 & 68.6 \\
\hline $\begin{array}{l}\text { P. J. Mair }{ }^{1}(99.94 \text { mole per cent) } \\
\text { Timmermans }\end{array}$ & $\begin{array}{l}68.7 \\
68.80\end{array}$ & $\begin{array}{l}-95.34 \\
-95.0\end{array}$ & $\begin{array}{l}1.3750 \\
1.375\end{array}$ & .659 & 368.9 \\
\hline
\end{tabular}

1 B. J. Mair, unpublished work.

2 J. Timmermans, J. chim. Phys., 24, p. 411; 1928.

3 G. Chavanne, Bull. soc. chim. Belg., 31, p. 331; 1922.

A sensitive criterion for purity of a hydrocarbon is its behavior during freezing. ${ }^{20}$ A comparison was made by B. J. Mair ${ }^{21}$ between the freezing behavior of a sample of very pure synthetic $n$-hexane

10 J. H. Bruun and M. M. Hicks-Bruun, B. S. Jour. Research, 5, pp. 933-42; 1930.

${ }_{20}$ E. W. Washburn, Ind. Eng. Chem., 22, p. 985; 1930.

21 Soe footnote 1, Table 3. 
prepared by him, and that of the $n$-hexane obtained by us. The comparison was made in the same apparatus, on the same day, and by using exactly the same technic in both cases. The time-temperature freezing curve of the $n$-hexane from petroleum is shown in Figure 5. The initial freezing point of the sample $\left(-95.67^{\circ} \mathrm{C}\right.$. $)$ is $0.33^{\circ} \mathrm{C}$. lower than that of the synthetic hexane $\left(-95.34^{\circ}\right.$ C. $)$. If the value 34.89 cal./g. ${ }^{22}$ is used as the heat of fusion of hexane, a depression of the freezing point of $0.33^{\circ} \mathrm{C}$. corresponds to a purity of 98.3 mole per cent. As it is not within the scope of this project to prepare hydrocarbons of the very highest purity, further treatment with chlorosulphonic acid of the hexane sample was omitted. However, the $n$-heptane fraction ${ }^{23}$ from petroleum, which has been treated for a longer time with chlorosulphonic acid, has freezing behavior (F. P. $-90.68^{\circ}$ C.), ${ }^{24}$ which indicates a high degree of purity.

Graph I in Figure 2 shows that normal hexane is present to a much greater extent than any of its isomers. All of the fractions boiling

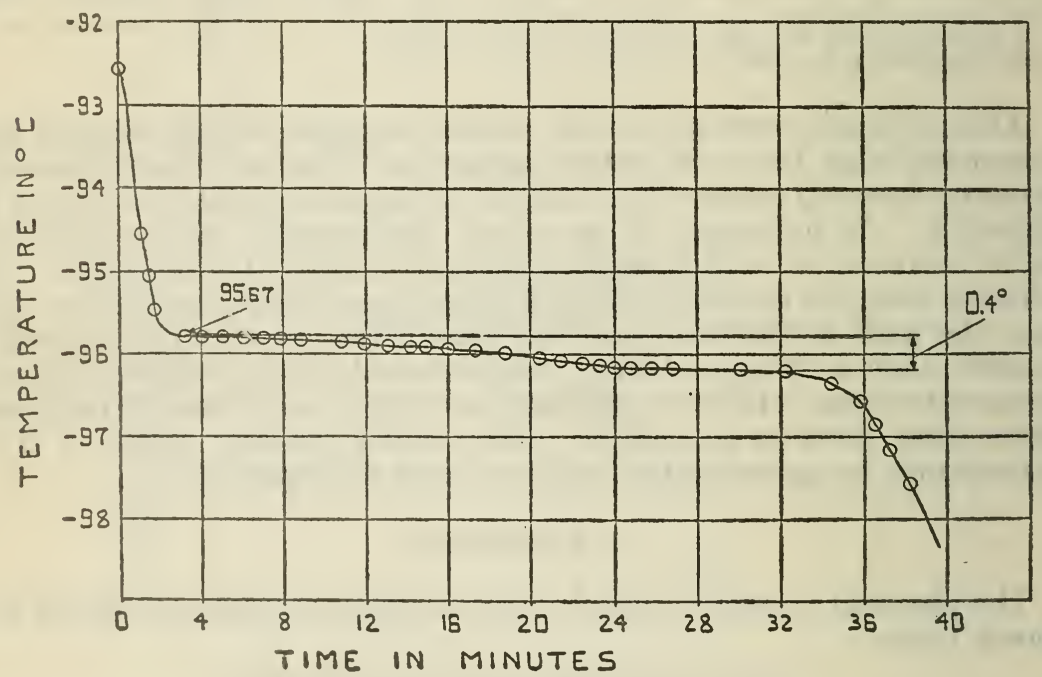

FIGURE 5.-Freezing curve for n-hexane

between $67^{\circ}$ and $72^{\circ}$ consist mainly of $n$-hexane. The minor constituents of these fractions are probably 3 -methylpentane, ${ }^{25}$ benzene, ${ }^{26}$ and methylcyclopentane. ${ }^{27}$ From a conservative estimate of the fractions distilling between $67^{\circ}$ and $72^{\circ} \mathrm{C}$., we may conclude that at least $10 \mathrm{~kg}$ of normal hexane, or one-third of 1 per cent, is present in the crude petroleum.

Graph I in Figure 2 gives us the following information as to the quantities of material distilling at the respective boiling points of the isomers of $n$-hexane:

\begin{tabular}{|c|c|}
\hline Mass of fraction (g) & Boiling range $\left({ }^{\circ} \mathrm{C}.\right)$ \\
\hline $\begin{array}{l}800 \\
800 \\
1,400 \\
3,700\end{array}$ & $\begin{array}{l}44 \text { to } 55 \text { (boiling point of } 2.2 \text {-dimethylbutane is about } 50^{\circ} \mathrm{C} \text {.). } \\
55 \text { to } 58 \text { (boiling point of } 2.3 \text {-dimethylbutane is about } 58^{\circ} \mathrm{C} \text { ). } \\
58 \text { to } 61 \text { (boiling point of } 2 \text {-methylpentane is about } 60^{\circ} \mathrm{C} \text {.). } \\
61 \text { to } 64 \text { (boiling point of } 3 \text {-methylpentane is about } 63^{\circ} \mathrm{C} \text {.). }\end{array}$ \\
\hline
\end{tabular}

n Parks and Todd, Ind. Eng. Chem., 21, p. 1236; 1929. $n$ 'To be discussed in a later paper.

a See footnote 20, p. 877 .
${ }^{28}$ See footnote 7, p. 870 .

26 See p. 873 .

${ }_{27}$ To be discussed in a later paper. 
Without further investigation these data do not justify any statcment concerning the relative amounts in which the isomers of hexane are present. In a previous investigation on the same petroleum by the authors ${ }^{28}$ however, it was found that all the isomers of $n$-hexane (except the 2.2-dimethylbutane which was not found) were found in the fractions boiling between $54^{\circ}$ and $75^{\circ} \mathrm{C}$. Based upon this fact as well as the Graph I in Figure 2, we might draw the conclusion that the isomers of $n$-hexane are present in the following approximate quantities:

3-methylpentane 0.18 (or less) per cent of the crude oil.

2 -methylpentane 0.09 (or less) per cent of the crude oil.

2.3-dimethylbutane 0.04 (or less) per cent of the crude oil.

The relation between the content of hexanes and the percentage of benzene in a given petroleum is important in that it determines the temperature at which the bulk of the benzene will distil. In the absence of the hexanes, the benzene will normally be present in the fractions which boil around $80^{\circ} \mathrm{C}$. When relatively small amounts of the hexanes are present some of the benzene will distil (as a constant boiling mixture) with the hexanes below $70^{\circ} \mathrm{C}$. after which the bulk of the benzene will come over at about $80^{\circ} \mathrm{C}$. If the hexane-benzene ratio is large most of the benzene will be found (as an azeotropic mixture) in the distillates boiling at about $70^{\circ} \mathrm{C}$.

\section{ACKNOWLEDGMENT}

The authors wish to express their thanks to E. W. Washburn, chief, chemistry division, Bureau of Standards, and director of American Petroleum Institute research project No. 6, under whose direction this investigation has been conducted.

Washington, February 27, 1931.

${ }^{28}$ See footnote 7, p. 870 . 